\title{
Entrevista com Emílio Domingos: Rio de Janeiro em batalhas de som, imagem e cotidiano
}

\author{
Tatiane Mendes Pinto*
}

Emílio Domingos é carioca, cineasta, pesquisador, roteirista e cientista social e une os dois elementos para criar documentários com foco em cultura urbana, particularmente da cidade do Rio de Janeiro. Mesclando elementos como hip hop, funk e o contexto social das ruas do Rio em suas obras - que incluem os documentários LAPA (2008) e A palavra que me leva além: histórias do hip hop carioca (2008) - e atuando como pesquisador em Mistério do Samba, Viva São João e Pierre Verger. Ele fala na entrevista sobre seus mais recentes filmes, A batalha do passinho ${ }^{1}$ (2012) e o mais recente, Deixa na régua ${ }^{2}$ (2016) . Nas duas obras, a pluralidade de narrativas constrói uma cidade de sons, imagens e afetos.

A entrevista teve lugar no Liceu de Artes e Ofícios, Rio de Janeiro/RJ a 21 de janeiro de 2018.

Tatiane Mendes Pinto: Eu queria primeiro falar de linguagem, falar dessa diferença que eu percebi entre os filmes, que tem planos completamente diferentes. Na batalha do passinho você trabalhou muito com PG (plano geral) e no Deixa na régua há muitos planos-detalhe com câmera subjetiva e essa linguagem ficou muito interessante. Eu queria também que você falasse sobre o processo para produzir o documentário, escolhas dos entrevistados, tanto um quanto outro filme.

Emílio Domingos: Não pretendo ser conhecido como um cineasta que estabeleceu um tipo de linguagem. Penso que a linguagem tem que estar associada ao filme e não quero me prender a nenhuma linguagem. Venho buscando estabelecer a cada filme uma linguagem relacionada diretamente ao tema e universo do filme. Experimentando a cada filme. Minha formação é em Antropologia, fui aprender sobre linguagem um pouco depois, a minha entrada no documentário já foi pelo lado de antropologia, das ciências sociais, come-

* Doutoranda em Comunicação Social. Universidade do Estado do Rio de Janeiro - UERJ, Pesquisadora do LACCOPS - Laboratório de Comunicação Comunitária e Publicidade Social-UFF, Pesquisadora do CAC-UERJ - Laboratório de Comunicação, Arte e Cidade. 20550-900, Rio de Janeiro, Brasil. E-mail: tatunha@ gmail.com

1. Ver: http://osmosefilmes.com.br/site/?page_id=8\#.WqMnPOjwbIU

2. Ver: http://osmosefilmes.com.br/site/?page_id=508\#.WqMpcOjwbIU 
cei trabalhando como pesquisador. A minha relação com o personagem sempre foi intensa mesmo antes de eu começar a fazer meus filmes. Eu já valorizava isso.

Dessa forma, quando eu escolho uma linguagem, escolho a partir do personagem, da locação, das situações. A linguagem estará a serviço disso. Em A batalha do passinho vivi uma situação específica que é fazer um filme de um fenômeno que estava em ebulição, que estava acontecendo e tive eventos inesperados que foram tomando conta do filme. Se a câmera não é tão íntima em diversos planos é pelo fato de eu estar observando, conhecendo e de certa maneira envolvido no meio daquilo.

Ao longo do filme a câmera vai se tornando mais intimista e a minha relação com os personagens, os dançarinos do passinho, também. Até pelos fatos que aconteceram durante o filme ${ }^{3}$ essa aproximação acabou acontecendo. $\mathrm{Na}$ Batalha eu comecei a filmar quinze dias após ter tido a ideia de fazer o filme. Conheci o passinho em 2008, mas fui convidado para ser jurado das provas e inicialmente desejava fazer um curta-metragem sobre os quatro dias de competição. Então, na sua origem, era um filme que seria simples. Mas, logo no início eu acabei mudando de ideia e decidi fazer um longa-metragem, porque eu percebi que a relação daqueles garotos com o passinho não era só um hobby de fim de semana, era uma extensão da própria vida, a identidade deles era o passinho então resolvi fazer um filme sobre o imaginário do dançarino do passinho, o ethos desses jovens. Não houve muito tempo para pesquisar ou até mesmo fazer um pré-roteiro. Durante o processo de filmagem fui pesquisando, aprendendo, trocando e construindo o roteiro.

A competição serviu como um laboratório, a câmera está observando, assim como eu, aprendendo como funciona. Então esse filme foi construído dentro desse quadro. Enquanto que o Deixa na régua é um projeto que demorou quatro anos para ser filmado. Eu tive a ideia em 2011 e só filmei em 2015. Em A batalha não houve nenhum financiamento. No Deixa na régua tentei vários editais, mas no Batalha eu não podia. $\mathrm{O}$ filme foi feito sem nenhum patrocínio. Com a equipe trabalhando de forma voluntária, que solidarizaram-se comigo, com as questões do filme, com aquele assunto e acabaram trabalhando ao longo de um ano e meio. Já no Deixa na régua não tive esse problema. Era um filme sobre o espaço do salão de barbeiro. Acreditava que três anos depois estaria ali. Esse tempo desde a ideia até a realização do filme foi usado para desenvolver a pesquisa, para escolher as locações, um filme que é mais esmiuçado no sentido da preparação.

3. Durante as filmagens do documentário, em 2012, o dançarino Gualter Damasceno Rocha foi assassinado quando voltava para casa. 
Primeiro eu conheci diversos barbeiros, depois me aproximei da competição chamada Batalha dos Barbeiros, ${ }^{4}$ fui a doze salões de barbeiros para ao final escolher aqueles três que aparecem no filme, e durante as idas aos salões, pude observar o tempo do salão, o tempo dos personagens, as posições de câmera e vi que - em termos de linguagem - a melhor forma de tentar traduzir aquilo ali seria sem minha presença como entrevistador. O objetivo seria tentar fazer com que aqueles personagens conduzissem a história através do cinema observacional. Assim o objetivo era tentar reproduzir o que se estava vendo. Durante a pesquisa percebi o espontâneo da oralidade que existe a partir da relação entre cliente e barbeiro. É um filme que valoriza a narrativa oral, se baseia nisso. Enquanto na Batalha o objetivo era tentar traduzir o fenômeno da dança, do movimento, eu não tinha uma pesquisa prévia, estava descobrindo o filme na prática e precisava traduzir para o espectador aquela dança, os códigos daquele grupo.

Os filmes são muito diferentes por isso, porque a Batalha é um filme com um movimento muito maior do que o Deixa na régua, é um filme que tem o ritmo do funk, tem o ritmo da música e do pensamento daqueles garotos que dançam. E o Deixa na régua tem o ritmo do salão, que tem em média vinte pessoas que ficam ali o dia todo esperando para cortar o cabelo, por isso as questões são diferentes e o próximo filme já será completamente diferente também.

TMP: E como vai ser o próximo filme?

ED: Estou me relacionando com o tema do próximo filme, que se chamará Favela é moda abordará o cotidiano de uma agência de modelos localizada na favela do Jacarezinho, Zona Norte da cidade do Rio de Janeiro. Minha relação com esse grupo começou em 2015 e esse tempo faz com que eu pense melhor sobre a linguagem do filme, qual o tipo de linguagem que se adequa mais ao que eu estou observando, ao que eu estou convivendo, porque não é somente uma observação, são três anos, você cria relações com o ambiente e os personagens. O filme não está distante do meu mundo cotidiano, faz parte das minhas relações diárias.

TMP: Em algum momento o antropólogo e o cineasta entram em conflito?

ED: Os dois se complementam muito. Não estou fazendo um trabalho de campo. Estou fazendo um filme. Entro nesses projetos e já penso como um filme. Carrego comigo a preocupação ética da antropologia, o olhar da convivência, de aprender e traduzir para o público o campo que estou vivendo.

4. Ver https://odia.ig.com.br/_conteudo/diversao/2016-03-31/batalha-dos-barbeiros-ganha -projecao-nacional-com-cortes-da-moda.html 
E nesse sentido as coisas estão juntas [a antropologia e o documentário], mas tenho a preocupação de contar uma história e aí entra a questão de que os filmes tem que ser interessantes. Não só a questão do conteúdo, mas sinto necessidade de um envolvimento, e tento desenvolver mecanismos para fazer os filmes.

TMP: Aquela câmera do Deixa na régua. É impossível não comentar. Ninguém quase olha para a câmera. Foi pré-combinado? Como funcionou isso?

ED: Quando a gente resolveu fazer o filme sob o viés do cinema direto - sem a presença ostensiva da câmera - eu resolvi ter uma conversa com os barbeiros e falei da importância que eles teriam como condutores do filme, dos temas. $\mathrm{O}$ que na verdade era o que eles costumavam fazer diariamente no salão, mal ou bem, atualmente as pessoas têm uma maior proximidade com a cultura do audiovisual, a ideia do cinema direto está nos reality shows, então as pessoas sabem um pouco, já convivem com essa forma de filmar. E tentei mostrar para eles aquilo que eu estava pensando e, além de concordarem, eles cumpriram muito bem a função de conduzir o filme e mediar minha relação com os clientes. Para isso houve uma preparação de frequentar o salão, entender como funciona, quem eram os clientes, quais assuntos se falavam ali. Insisti em ir sempre no mesmo dia ao salão para acompanhar aquele mesmo grupo. Os clientes cortam o cabelo toda semana, então o grupo se conhece e isso gera uma conversa espontânea entre eles. Tem a questão de encontrar os ângulos e fazer com que eles comecem a naturalizar minha presença. No primeiro dia de filmagem geralmente era muito difícil, tanto sob o ponto de vista técnico quanto pela minha presença, e até mesmo para o fotógrafo. Alteramos fisicamente o espaço do salão, por exemplo, prateleiras que ficavam nas costas do fotógrafo foram retiradas. A gente mudou o eixo do espelho para conseguir pegar o barbeiro. O espelho saiu do lugar para conseguir enquadrar o cliente que está cortando o cabelo e ter o barbeiro no fundo do plano. O filme se dá através da interação entre o cliente que está cortando o cabelo e o barbeiro e é como se fosse uma arena, um microcosmos e todo mundo participa.

TMP: Alguma dificuldade além das técnicas?

ED: Inicialmente era difícil achar o eixo da câmera, e fazer com que os clientes não olhassem para ela. Lógico que tem uma questão que ajudou muito, que é a vaidade deles. Estavam mais preocupados com o resultado do corte do que se havia uma câmera lá, então a gente colocou uma câmera quase no eixo do espelho, mas a pessoa está olhando para o espelho porque ela quer ver o resultado do corte. Outra coisa foi a mediação dos clientes. Porque é muito 
comum em um salão as pessoas falarem ao mesmo tempo, momento este em que os barbeiros pediam para que cada dos clientes falassem cada um por vez. Apesar de ser um espaço do meu convívio, de eu estar lá, eu era um estranho inicialmente e não poderia pedir para as pessoas ficarem quietas ou falarem cada uma de uma vez. Somente o barbeiro poderia fazer isso. Então eu me dirigia ao barbeiro, para que ele falasse com os clientes. Não poderia fazer esse tipo de intervenção, senão eu não teria o filme.

TMP: Fala-se muito hoje em dia do gênero Favela movies, filmes produzidos sobre favelas. Parece que teus filmes não estão nessa classificação. Queria que você falasse um pouco sobre isso.

ED: Alguns dos meus filmes se passam nas favelas, mas eu não considero que sejam Favela movies.

TMP: E o que vc considera Favela movies?

ED: Eu acho que o gênero Favela movies ficou conhecido com o Cidade de Deus (Meirelles; Lund, 2002) e são filmes de um gênero próximo ao policial e que tratam a favela como um espaço de conflito de forças, como policiais versus traficantes. Acho que esse é o principal tema, o principal conflito das histórias. Meus filmes não. Apesar de serem rodados na favela, tentam dar conta de um universo muito mais amplo do que isso. Não que não haja violência. A violência às vezes perpassa o filme, mas não é o tema central e eu tento ver a favela como espaço de criação, de práticas cotidianas que muitas vezes o Favela movie não mostra. Meus filmes demonstram uma certa intimidade com os personagens, uma certa complexidade do cotidiano, não se reduz à violência. Então eu acho que eu não me encaixo nesse gênero.

TMP: Antes de ver seu filme [Deixa na régua], lendo sobre, mas sem ter visto o filme, eu tinha uma perspectiva totalmente diferente, algo mais do cotidiano, sem tanto a questão da identidade, mas é interessante porque como você fala que os assuntos perpassam e eu queria saber como isso funciona. Porque, ao mesmo tempo que você tem no salão aquele grupo de garotos sentados, querendo cortar o cabelo para ficarem bonitos porque tem o baile, porque eles vão sair, você tem eles falando sobre racismo, sobre gênero, falando sobre como eles vêm aquele universo. Como isso funciona para vc?

ED: No Deixa na régua filmei por cinco meses naqueles espaços buscando uma síntese dessa relação, dessas experiências e aí tem um trabalho grande de 
edição da Jordana Berg, ${ }^{5}$ tem muita experiência de montagem, é uma grande montadora. O documentário tem muito da mão dela, apesar de termos um préroteiro. A arte de sintetizar isso com um fio condutor, aquelas histórias terem uma intercessão, uma narrativa, acho que foi um grande trabalho dela. Uma característica da Jordana é a sensibilidade.

TMP: Logo nos primeiros minutos do filme, um dos personagens fala que ele tinha ido ao baile, só que ele não tinha cortado o cabelo, não tinha feito a sobrancelha e estava se sentindo oprimido. O que seria isso?

ED: Isso é a síntese da vaidade masculina.

TMP: Você pode falar um pouco disso?

ED: Tem uma frase dita em off por um dos meninos, que é personagem, que acabou não entrando no filme, mas que sintetiza bem isso: "se eu tenho 20 reais para passar o fim de semana e eu posso ir ao baile ou cortar o cabelo, eu posso cortar o cabelo e ficar em casa me sentindo bem ou estar em público e as pessoas ficarem me olhando, vendo que eu não cortei o cabelo. E eu ficaria me sentindo mal, então eu prefiro vir ao salão de barbeiro toda semana e não ter dinheiro para sair". Acho que isso denota a importância que tem, como esse jovem masculino contemporâneo está pensando.

TMP: E esse atravessamento dos estereótipos, do feminino, do masculino, com os quais os clientes do salão vão dialogando muito tranquilamente ali.

ED: Acho que essa é uma questão importante do filme. Retratar uma nova vaidade masculina que, de certo modo, tem fronteiras com o feminino: como fazer a sobrancelha, fazer a unha. Provavelmente nem todas as mulheres vão semanalmente ao salão, para essa juventude masculina essa frequência é fundamental. Esse tipo de vaidade era muito associada ao universo feminino até bem pouco tempo atrás, então, o filme mostra que esses hábitos também fazem parte do universo masculino. No filme, percebemos que existe um "novo homem" que se coloca em alguns momentos no lugar das mulheres em termos estéticos, mas isso não elimina a presença do machismo que ainda é muito intensa nos salões de barbeiros. Acho que essa mudança se dá primeiro de forma estética para depois vir através do comportamento. Eles ainda estão no salão para conquistar as mulheres, apesar deles terem uma dificuldade de se colocar no lugar das mulheres no cotidiano.

5. Montadora de cinema brasileira. Seu primeiro trabalho profissional foi em 1983. Jordana é reconhecida como especialista na montagem de filmes documentários. De 1995 até 2014 trabalhou com o cineasta Eduardo Coutinho. 
TMP: Só tem uma mulher [nos salões], né?

ED: Sim. A menina que aparece no filme é uma amiga do barbeiro, quase uma irmã de consideração, que vai no salão para conversar. E como o Deivão [personagem] estava para se tornar pai e ela tinha acabado de ser mãe, eles trocaram experiências. Existia uma curiosidade por parte dele em relação ao parto natural ou a cesariana, e ela defende a cesariana. Ele achava mais interessante um parto natural. Ela prega a praticidade.

TMP: Eu queria agora falar um pouco esse documentário brasileiro contemporâneo. Em um universo em que a gente tem cada vez mais concentração de meios de produção, de empresas, em que os cineclubes diminuem, são pouco frequentados, a ausência de editais, como fazer cinema nesse cenário?

ED: Eu trabalho com documentário há 20 anos. Comecei como pesquisador no documentário do Lula Buarque de Hollanda, ${ }^{6}$ Pierre Verger - mensageiro entre dois mundos [Hollanda, 2000]. Sempre foi difícil. Eu, por exemplo, dirigi muitos filmes sem patrocínio, curtas-metragem e até mesmo o Batalha do passinho. Eu trabalhava como pesquisador para projetos de outras produtoras, recebia por isso e investia o dinheiro nos meus filmes. Meus filmes sempre foram muito coletivos, a equipe é formada por pessoas que são apaixonadas pelo documentário, e que valorizam essas experiências. Aprendemos na prática a fazer os filmes. Hoje, por uma questão de profissionalização, minha prioridade é fazer filmes com patrocínio, com apoio de editais e leis de incentivo, mas é preciso aprender o funcionamento, os meandros disso. A Osmose Filmes, ${ }^{7}$ minha produtora, é resultado disso. Há cinco anos decidi jogar a sério esse jogo, aprender como funciona, a necessidade de ter um CNPJ e entender as suas regras. Na Osmose, que é basicamente uma produtora de documentários, eu tenho tido essa experiência. Tenho ido a eventos como o DOC SP, ${ }^{8}$ participado de rodadas de negócios, fui ao Brasil CineMundi, dentro da Mostra de Cinema de Belo Horizonte (Minas Gerais). Estou aprendendo a me relacionar com parceiros, produtores e co-produtores dos filmes, e existe todo um universo por trás disso, em conhecer festivais, canais internacionais que se interessam em produzir documentário e você acaba criando uma dinâmica para desenvolver os projetos antes dos filmes. Hoje eu tenho cerca de seis projetos que venho desenvolvendo.

TMP: Você pode citar um deles?

6. Diretor de cinema, produtor e documentarista brasileiro.

7. Ver http://osmosefilmes.com.br/site/

8. http://spcine.com.br/sobre/ 
ED: O Favela é moda é um deles. É o terceiro da trilogia do corpo [junto com Batalha do passinho e o Deixa na régua], que estou desenvolvendo há algum tempo. É preciso ter diversos projetos para saber que projeto se adequa mais ao perfil de cada plataforma porque quando você vai para uma rodada de negócios, é necessário ter sua cartela de filmes, de projetos, para que as pessoas entendam o que você faz. É preciso mostrar o que você projeta para o futuro, quais são suas questões. Você não pode pensar somente no projeto que está fazendo agora. Tem que estar sempre pensando além. A Osmose possui um núcleo de criação que é um grupo de pessoas com quem eu trabalho há muito tempo, com sintonia de ideias. A gente escreve projetos juntos e se reúne periodicamente para desenvolver, acertar o roteiro, para o projeto ganhar força. É um exercício coletivo com pessoas como o Simplício Neto, Fred Coelho e Tatiana Bacal, esse grupo funciona como um laboratório de desenvolvimento de ideias. Tenho dois grandes sócios na produtora, o Yan Motta e a Clarice Saliby. O Yan é montador e atuou recentemente em dois filmes do Belisário Franca, Menino 23 [Franca, 2016] e o novo filme dele sobre a Guerrilha do Araguaia, o Soldados do Araguaia [Franca, 2018] e Clarice fez um curta premiado chamado Efeito Casimiro [Saliby, 2013], e no momento faz um longa-metragem sobre o apresentador Cid Moreira. São pessoas ligadas ao documentário e temos uma dinâmica intensa de troca de ideias nos projetos uns dos outros. São pessoas que, além de serem apaixonados pelo documentário, tem vontade de construir juntos, independente de estarem trabalhando no projeto e eu acho isso incrível.

TMP: Você milita nesse lugar de que fazer documentário, como vocês pensam o documentário como uma ferramenta de transformação social?

ED: O cinema é uma forma de transformação social. Durante o tempo do filme, os espectadores se desligam das práticas cotidianas ou relacionam o que veem com a sua vida. O cinema permite fazer uma imersão num outro universo. É um momento de reflexão, o documentário se caracteriza muitas vezes por levar experiências de outras realidades. Cinema é isso, tentar viver outras experiências durante aquele período em que você está no cinema e de certa maneira ele leva essa ilusão de que você está aprendendo e convivendo com os personagens do filme. O público de documentário tem uma relação muito intensa com os filmes. Então quando você vê um documentário, você acaba experimentando outra forma de viver uma vida que não é a sua, até mesmo quando é uma realidade próxima da sua, faz repensar algumas coisas, as histórias e as suas experiências de vida.

TMP: Até que ponto é possível manipular, dialogar com esse real ? 
ED: Eu particularmente não tenho interesse pelo uso da linguagem ficcional no documentário, gosto de me surpreender durante o processo, de não ter tanto controle. O que me dá prazer no fazer documentário é essa constante capacidade de me surpreender com a história, com os acontecimentos, com os rumos que as coisas vão tomar. Talvez, no futuro, eu faça filmes que tenham interseção com a ficção, mas no momento não. Eu admiro quem faz e fez como, por exemplo, Jean Rouch.

TMP: Algum brasileiro?

ED: O Afonso Uchoa. É da minha geração, um pouco mais novo do que eu e faz isso muito bem lá no Vizinhança do tigre [Uchoa, 2014] e tem uma diretora de Belo Horizonte, Juliana Antunes que dirigiu o Baronesa [Antunes, 2017], um filme bem interessante, que tem uma dose grande de ficcionalização. Outro diretor que eu gosto muito é o Adirley Queirós, com Branco sai, preto fica [Queiroz, 2014], que tem muito dessa linguagem de ficção com documentário, essa interface entre os dois.

TMP: Algum documentarista português, que você tenha visto e que possa destacar?

ED: Existem dois diretores portugueses que não são exatamente documentaristas mas que eu gosto muito. Pedro Costa, diretor de Cavalo dinheiro, e Miguel Gomes que dirigiu a série de filmes As 1001 noites.

TMP: Já que a gente está emendando essa coisa de cinema brasileiro e cinema português vc acha que o cinema pode construir esse território, se pode criar um espaço, através da narrativa, esse espaço sensível, estético?

ED: Sim, acho que tem muitos diretores que fizeram isso, criaram um traço, uma forma de fazer os filmes. Eu quero ser conhecido como um diretor que valoriza o universo filmado, não pela linguagem, que cria uma intimidade entre o público e os personagens, espero que ao ver o filme o espectador saia dali com uma experiência real de interação com os personagens. Esse é meu objetivo.

TMP: Você costuma ir nas sessões de exibição do seus filmes . Fala um pouco sobre isso e sobre a exibição do Deixa na régua. Foi diferente da Batalha do passinho?

ED: Eu gosto muito de ir nas sessões e acho que faz parte do processo de filmagem, ver como as pessoas recebem o filme, como ele sensibiliza. Isso me dá muito prazer, conversar sobre a filmagem, sobre os personagens e muitas vezes levar os protagonistas para debaterem o filme. No caso dos barbeiros existe 
uma dificuldade, porque eles trabalham muito geralmente não tem tempo, mas as sessões em que estavam presentes foram incríveis, no Festival do Rio, nas universidades, etc. Fizemos uma sessão no tradicional Cine ODEON e a sessão estava lotada. Foi emocionante, todos ficaram muito felizes.

TMP: Como foi quando eles se viram na tela?

ED: O cinema serve para pensar o mundo. Eu gosto, gosto quando os personagens veem o filme, e ao comentar o filme no debate, eles colocam outras camadas. Muitas vezes não sou da mesma camada social do grupo filmado, dos barbeiros, dos dançarinos do passinho ou frequentadores do salão, então existe um estranhamento muito saudável, que aproxima o que é um princípio básico da antropologia. É fascinante estar numa projeção que após o filme as pessoas dizem que tinham uma visão antes e sentaram ali e se surpreenderam, repensaram os pré-conceitos que tinham sobre aquele tema. Eu vivi isso com o Batalha do passinho e o Deixa na régua. O Batalha do passinho gerou grande interesse do público, circulou muito, mais de trinta países, teve matérias na $C N N$, no The Guardian, etc. O Deixa na régua é mais brasileiro, um filme de conversas com o jeito de falar do carioca que talvez seja difícil para quem é de fora. Ele foi muito bem no Brasil, foi mais premiado do que o Batalha e eu tive um frio na barriga, porque os dois são muito diferentes em termos de linguagem e eu não sabia qual era a expectativa do público. Eu temia que houvesse uma decepção. Mas ele foi muito bem recebido no Brasil, o que me tranquilizou bastante.

TMP: Você disponibilizou A batalha do passinho para cineclubes.

ED: O cineclube é um braço importante do filme, funciona muito bem na cadeia distributiva. São grandes parceiros, é como se fosse uma "ilha de cinema" no meio do oceano, na qual você pode conversar com o público, pode ter uma relação mais direta com o público. Você consegue levar o cinema para lugares que muitas vezes não tem o equipamento, às vezes nem a sala. Vivemos um boom de cineclubes nesse século no Rio de Janeiro. Fiz muitas sessões em comunidades, com equipamentos básicos, mas com grande público e isso fez com que os filmes fossem muito vistos, tivemos sessões no meio de descampados, para quinhentas pessoas. As pessoas se viam na tela e virava surround, porque interagiam tanto que os sons se espalhavam por todos os lugares. Era tão interessante olhar para a plateia , a ver a emoção das pessoas ao seu lado, quanto ver o filme.

TMP: Quais foram as locações dos filmes? 
O Batalha do passinho foi filmado em vários lugares, as competições acontecerem em três comunidades na Tijuca: ${ }^{9}$ Morro do Borel, Andaraí e Salgueiro e a final foi no SESC [Serviço Social do Comércio]. O início do filme é um pouco disso. Eu fui fazendo meu campo, conhecendo meus personagens. Como eu disse anteriormente, eu fui convidado para ser jurado [da competição] e recusei, achei que minha contribuição maior seria filmando. Conheci o passinho em 2008 pelo youtube e me tornei fã dos garotos.

TMP: Como não ser?

ED: Sim, como não ser? A partir daí eu comecei a ir para as comunidades dos personagens, na Cidade de Deus, Piedade, Campinho, Morro do Barbante, Manguinhos, Morro da Providência. O Deixa na régua eu filmei em três salões dois da Zona Norte do Rio, um no Morro da Caixa D'água, em Quintino, e outro na Vila da Penha. E o terceiro na baixada, em Piabetá, distrito de Magé o salão do Belo é na Vila da Penha, o do Ed é no Morro da Caixa D'água e o do Deivão é em Piabetá, quase zona rural.

TMP: Como foi quando eles viram o filme?

ED: Sempre exibo o filme para os personagens antes do corte final, e essa sessão foi muito interessante porque é um dos momentos em que eu estou mais nervoso para saber se eles tem alguma questão em relação ao filme, se eles querem que mude. Nesse filme parecia uma sessão da tarde com pipoca, em que eles ficavam comentando um sobre o salão do outro, falando sobre o próprio salão e pensando sobre questões do trabalho, ferramentas, tipo de cliente, tendo um olhar de empresários. $\mathrm{O}$ filme foi a possibilidade deles se conhecerem melhor. $\mathrm{O}$ filme tem muito do ponto de vista deles. O que pensam, o que sentem com o mundo, mesmo que nem sempre eu compartilhe das mesmas opiniões sobre alguns temas. Eu ficava preocupado com algumas coisas que eles disseram, mas pela convivência, eu sabia que era o que eles pensavam. Estava muito preocupado se eles iam pedir para tirar alguma cena quando um deles me disse: "Emílio, por favor, não vem filtrar a gente, a gente é assim mesmo. Deixa assim e não tem que tirar nada não, a gente pensa assim. E a gente estava bem consciente de que estava sendo filmado. Deixa isso assim". Existe um receio quando você está montando, é um exercício de ir e vir e se colocar no lugar do outro, e voltar a si. Talvez seja um choque para mim porque eu não penso igual, mas isso faz parte do processo. Ser diferente. Mostrar como eles são. O filme é resultado de uma relação.

TMP: Em algum momento você pensou em desligar a câmera?

9. Bairro da Zona Norte do Rio de Janeiro. 
ED: Eu saí do salão várias vezes. No Batalha do passinho eu não filmei o enterro do Gambá pois fiquei muito abatido, não tive força para ir. É muito difícil para mim até hoje. Fiquei tão abatido que não sabia se ia continuar o filme. De certa maneira, fiquei sem rumo por um tempo, uma semana, dez dias sem pensar em nada e voltei ao filme por causa dos garotos que foram se fortalecendo através de laços de solidariedade, de encontros e fui me aproximando de alguns, nessa experiência da dor, da perda. Mas eu não filmei enterro. Nem é meu feitio filmar enterro. O filme já é muito duro sem esse tipo de imagem.

TMP: Em algum momento algum daqueles meninos te perguntou como filmar, teve alguma curiosidade, como você acha que o documentário chega até eles?

ED: Estou trabalhando com o Cebolinha, protagonista do Batalha do passinho. Ele me contratou para fazer um filme de ficção, ganhou o edital e me convidou para filmar. Então acho que o filme mexeu com aqueles garotos, porque eles tinham como estratégia de divulgação do trabalho o uso do audiovisual, a internet. O cinema foi mais uma plataforma para eles. Acho que a constante ida deles nos debates fez com que mudassem até a relação enquanto dançarinos. O cinema de fato mudou a relação deles com o mundo. O Cebolinha ser roteirista e fazer uma web série do passinho mostra o quanto ele quer se envolver com isso e o quanto ele acha importante.

TMP: E no Deixa na régua? Você sentiu isso? Essa sensibilidade com a câmera?

ED: O filme trata de uma profissão que é muito presente na sociedade, mas não é tão valorizada. Decidi fazer um filme sobre esses barbeiros do Deixa na régua, porque percebi o quanto eram importantes para essa geração, o quanto do trabalho deles se assemelha ao trabalho artístico, de um escultor. Para além disso, as pessoas quando vão a um salão saem transformados, mais felizes, pela modificação corporal e também pela conversa. O salão é um espaço onde eles podem se expressar integralmente, falar realmente tudo que pensam e sentem. É importante na sociedade em que a gente vive hoje ter esses espaços, num tempo em que as relações virtuais ganharam uma força tão grande, acredito que isso [a interação ao vivo] é real e importante. É um dos poucos espaços do encontro, da conversa, onde as pessoas podem ir. Tem gente que vai no salão e não corta o cabelo, vão somente para conversar. O filme é o reconhecimento de um trabalho que tem uma importância social grande que vai além da valorização estética. 
TPM: Para terminar, você poderia falar da moção que você recebeu, da Secretaria de Cultura do Estado?

ED: Recebi uma moção que foi uma ideia do DJ TR, um dos pioneiros do hip hop aqui no Rio de Janeiro e fiquei muito feliz. Foi um reconhecimento por parte do movimento do hip hop. Fiz três filmes sobre o assunto, eu não sou DJ, não sou bboy, ${ }^{10}$ não sou grafiteiro, não sou $\mathrm{MC}$, logo, teoricamente eu não faço parte, não sou um dos quatro elementos da cultura hip hop, mas eles valorizaram meu trabalho de documentar a cultura hip hop no Estado do Rio e fiquei muito feliz, muito surpreso por ter o reconhecimento das pessoas que fazem parte desta cultura a qual eu filmei. É emocionante porque você faz filmes para as pessoas que se predispuseram a contar suas histórias e conviver com você durante aquele período. Então esse feedback é incrível. Ganhei também uma medalha Pedro Ernesto da câmara dos vereadores e esse tipo de coisa me dá ânimo. O trabalho por vezes é muito duro, é muito difícil e qualquer tipo de reconhecimento é válido. Tem gente que não consegue isso em vida, então esse reconhecimento do mundo formal, da Câmara é importante. Mais do que isso, reconhecimento dos meus personagens, tenho uma relação com eles até hoje. Pessoas que filmei em 1999 e que estarei junto em março, pois fui convidado para um evento que um deles está organizando. Então essas relações se estendem e continuam para além do cinema e do documentário e essa é a principal moção e premiação que eu poderia receber. Saber que essas pessoas reconhecem a importância do meu trabalho e se sentem felizes de terem suas histórias contadas. Cada filme é uma história, um envolvimento. Eu estou ansioso para acabar o próximo, o Favela é moda, conseguimos o patrocínio. Fazer documentário é um exercício de paciência. Você gera expectativa em muita gente. É uma responsabilidade, então é preciso levar as coisas com o máximo de serenidade. Para que ele [o filme] aconteça quando puder acontecer. Têm filmes que necessitam que você saia filmando naquele momento. Por sorte, tenho uma equipe que se identifica e que aceita filmar mesmo sob risco. Sou muito grato a isso. Fazer filmes é uma extensão da minha vida, seria muito frustrante não conseguir filmar. O Favela é moda será rodado na favela do Jacarezinho e circulará também por outros lugares, estou acompanhando o desenvolvimento da agência, o cotidiano das modelos e o glamour, além do mundo real, que nem sempre é glamoroso.

10. Aquele que se expressa através de movimentos,combinados com o ritmo das batidas do Hip-hop. Ver: www.dancaderua.com/artistas/bboys/o-que-e-um-bboy 
Entrevista com Emílio Domingos: Rio de Janeiro em batalhas de som, imagem e cotidiano

\section{Filmografia}

Branco sai, preto fica (2014), de Adirley Queirós.

Cidade de Deus (2002), de Fernando Meirelles e Kátia Lund.

Efeito Casimiro (2013), de Clarice Saliby. Disponível em: http://portacurtas.or $\mathrm{g}$.br/filme/?name=efeito_casimiro.

Menino 23 (2016), de Belisário Franca.

Nossa música (2005), de Jean-Luc Godard.

Pierre Verger - mensageiro entre dois mundos (2000), de Lula Buarque de Hollanda.

Soldados do Araguaia (2017), de Belisário Franca.

Vizinhança do Tigre (2014), de Affonso Uchoa. 